\title{
PENINGKATAN KESEGARAN JASMANI MELALUI MATAKULIAH PENCAKSILAT MAHASISWA ILMU KEOLAHRAGAAN
}

\author{
Ginanjar Nugraheningsih $^{1)}$, Yulius Agung Saputro ${ }^{2)}$ \\ Program Studi Ilmu Keolahragaan Fakultas Keguruan dan Ilmu Pendidikan \\ Universitas Mercu Buana Yogyakarta \\ email: ${ }^{1}$ ginanjar@mercubuana-yogya.ac.id \\ yulius@mercubuana-yogya.ac.id
}

\begin{abstract}
ABSTRAK
Penelitian ini bertujuan mengetahui peningkatan kesegaran jasmani setelah mengikuti matakuliah pencak silat mahasiswa Ilmu Keolahragaan. Instrumen tes multy stage fitness test digunakan untuk mengukur kapasitas kardiorespirasi (VO2 Max) mahasiswa Ilmu Keolahragaan. Populasi 38 mahasiswa seluruhnya digunakan sebagai sampel penelitian (total sampling). Metode penelitian yang digunakan adalah pra-eksperimen dengan rancangan one group pretest posstest design. Teknik analisis data menggunakan uji-t berpasangan setelah melalui tahap uji prasyarat. Hasil penelitian diketahui nilai $t_{\text {hitung }}>t_{\text {tabel }}=2,681>2,434$ ( $\mathrm{p}$ value $=0,009<0,05$ ). Maka Ho ditolak, artinya ada perbedaan rata-rata kesegaran jasmani pretest dengan posstest. Perbedaan ratarata (mean difference) sebesar 4,01842 (40,4789-36,4605) posttest lebih tinggi daripada pretest. Melalui matakuliah pencak silat akan memberikan pengaruh peningkatan kesegaran jasmani.
\end{abstract}

Kata Kunci: pencak, silat, kesegaran jasmani

\begin{abstract}
This study aims to determine the increase in physical fitness after participating in the martial arts subjects of Sport Sciences students. The multy stage fitness test was used to measure the cardiorespiratory capacity (VO2 Max) of Sports Science students. The population of 38 students was used as a research sample (total sampling). The research method used was a preexperimental design with one group pretest posstest design. The data analysis technique used paired $t$-test after passing the prerequisite test phase. The results of the study are known tcount $>t$ table $=2,681>2,434$ ( $p$ value $=0.009<0.05$ ). So Ho is rejected, meaning there is a difference in the average physical fitness of the pretest and the posstest. The mean difference (mean difference) of 4.01842 (40.4789-36.4605) posttest is higher than the pretest. Through pencak silat courses will give effect to increase physical fitness.
\end{abstract}

Keywords: pencak, silat, fitness, physical

$\bowtie$ Alamat korespondensi:

E-mail: ginanjar@mercubuana-yogya.ac.id @ 2019 IKIP BUDI UTOMO MALANG Info Artikel

Dikirim : : 11 September 2019

Diterima $\quad: 21$ Oktober 2019

DOI $\quad:$ https://doi.org/10.33503/jp.jok.v3i1.560 


\section{PENDAHULUAN}

Tujuan Negara Kesatuan Republik Indonesia pada batang tubuh UUD 1945 alinea 4 yakni: (1) memajukan kesejahteraan umum, (2) melindungi segenap bangsa dan seluruh tumpah darah Indonesia, (3) mencerdaskan kehidupan bangsa, dan (4) ikut serta dalam usaha perdamaian dunia (UUD 45, 1945). Bertolak dari tujuan negara ini maka berdirilah satuan pendidikan formal, nonformal dan informal pada setiap jenjang dan jenis pendidikan. Pada jalur pendidikan formal terdapat jenjang pendidikan tingkat pendidikan anak usia dini, SD, SMP, SMA, dan Perguruan Tinggi (PT) yang masing-masing memiliki kurikulum muatan lokal. Dalam muatan kurikulum lokal pendidikan formal olahraga dewasa ini terdapat kurikulum Pencak Silat. Pencak silat masuk dalam muatan lokal sebagai bentuk pengenalan, pengembangan, memajukan nilai history budaya asli Indonesia yang diwariskan dari nenek moyang Indonesia diajarkan melalui pendidikan. Pencak silat yang tadinya merupakan suatu kegiatan ekstrakurikuler telah berubah menjadi kurikulum yang masuk dalam muatan intrakurikuler muatan lokal mata pelajaran Penjas Orkes (Republik Indonesia, 2005).

Menurut (Permendikbud RI No. 20, 2016) yang dikutip oleh (Mayanto, 2019), "Sistem pendidikan nasional di dalamnya terdapat muatan kurikulum yang terdiri dari berbagai kompetensi dan materi yang sengaja dirancang untuk membelajarkan siswa salah satunya yaitu kurikulum penjas orkes yang di dalamnya terdapat pencak silat”. Selain itu, menurut (Widodo \& Kusnanik, 2013), "Pendidikan jasmani seseorang dapat maksimal jika memiliki tingkat kesegaran jasmani yang baik”. Disamping itu menurut (Saputro, 2018), “Kebugaran jasmani merupakan salah satu komponen dalam mencapai suatu produktivitas yang baik. Kebugaran jasmani yaitu kesanggupan dan kemampuan tubuh melakukan penyesuaian terhadap pembebasan fisik yang diberikan kepadanya tanpa menimbulkan kelelahan yang berlebihan. Setiap orang membutuhkan kebugaran jasmani yang baik, agar dapat melaksanakan pekerjaannya dengan efektif dan efisien".

Dalam hal ini mahasiswa pada prodi Ilmu Keolahragaan merupakan bibitbibit calon pendidik ataupun pelatih yang akan terjun secara langsung di masyarakat. Apabila memiliki kes. jasmani yang baik sebagai mahasiswa calon 
pendidik/pelatih maka akan lebih efektif dalam meningkatkan performance, sehingga kinerja fisik dalam berolahraga, mengikuti kegiatan akademik, mengikuti single event ataupun multi event yang sifatnya olahraga fisiknya tetap terjaga. Selain itu mau tidak mau mereka akan menyampaikan materi pencak silat di masyarakat sehingga diperlukan kesegaran jasmani yang baik, tidak cepat lelah, tidak cepat stress, tidak loyo, dan lain sebagainya memiliki kondisi tubuh yang siap dan segar. Pembahasan pada penelitian ini terfokus pada peningkatan kesegaran jasmani melalui matakuliah pencak silat mahasiswa Ilmu Keolahragaan.

Adapun rumusan masalah dalam penelitian ini yaitu, "Apakah terdapat pengaruh peningkatan kesegaran jasmani melalui matakuliah pencaksilat mahasiswa Ilmu Keolahragaan?” Untuk menghindari cakupan yang sangat luas maka penelitian ini dibatasi pada peningkatan kesegaran jasmani melalui matakuliah pencaksilat mahasiswa Ilmu Keolahragaan, FKIP, UMBY yang mengambil matakuliah pencaksilat di semester 2. Adapun tujuan penelitian ini yaitu untuk mengetahui peningkatan kesegaran jasmani melalui matakuliah pencak silat mahasiswa Ilmu Keolahragaan. Penelitian ini merupakan penelitian pendahuluan untuk menggali kesegaran jasmani mahasiswa dan mengarah bidang keilmuan olahraga.

Menurut (Hasan, 2008), "Kesegaran jasmani adalah kemampuan tubuh seseorang untuk melakukan tugas dan pekerjaan sehari-hari dengan giat dan waspada tanpa mengalami kelelahan yang berarti, serta masih memiliki cadangan energi untuk menghadapi hal-hal darurat yang tidak terduga sebelumnya”. Menurut (Resmana, Saichudin, \& Januarto, 2014) yang dikutip (Biliandri, Supriyono, Pujianto, \& Priyono, 2018), "Komponen dari kesegaran jasmani terdiri dari 10 komponen, yaitu: 1) kekuatan (strength), 2) daya tahan (endurance), 3) daya otot (muscular power), 4) kecepatan (speed), 5) daya lentur (flexibility), 6) kelincahan (agility), 7) koordinasi (coordination), 8) keseimbangan (balance), 9) ketepatan (accuracy), 10) reaksi (reaction). Menurut Muhajir yang dikutip oleh (Saputro, 2018), "Kesegaran jasmani merupakan sari utama cikal bakal dari kebugaran jasmani secara umum”. Jadi apabila orang dalam keadaan segar salah satu aspek pokok yang nampak adalah keadaan 
penampilan jasmaninya. Dengan demikian seseorang tidak dapat mencapai kesegaran jasmani secara menyeluruh atau umum tanpa didasari oleh keadaan kesegaran jasmani yang baik. Faktor-faktor yang mempengaruhi kebugaran jasmani yaitu umur, jenis kelamin, genetik, makanan dan pola hidup sehat (Yusuf, 2018).

Menurut Sugiharto yang dikutip oleh (Prayuda \& Firmansyah, 2017), "VO2 max adalah jumlah maksimal oksigen yang dapat dikonsumsi selama aktivitas fisik yang intens sampai akhirnya terjadi kelelahan dan VO2max dinyatakan dalam liter/menit/kilogram berat badan. VO2max ini dapat membatasi kapasitas kardiovaskuler seseorang, maka VO2max dianggap sebagai indikator terbaik dari ketahanan aerobik".

Olahraga dapat dikatakan sebagai kebutuhan hidup untuk mencapai kesehatan jasmani dan memberi pengaruh baik terhadap perkembangan rohani, sehingga ada efisiensi kerja alat-alat tubuh, keteraturan peredaran darah, pernafasan dan pencernaan. Olahraga juga dapat membantu karakteristik masyarakat menjadi lebih baik dalam hidup, dan membentuk keselarasan jiwa dan raga sehingga mencapai keselarasan individual-sosial yang mandiri (Setiawan, 2012). Pencak silat merupakan salah satu bentuk olahraga yang diajarkan berupa mata kuliah teori dan praktek. Menurut (Iswana \& Siswantoyo, 2013) yang dikutip oleh (Kuswanto, 2016), "Prinsip dasar olahraga pencak silat adalah membela diri yang di dalamnya terdapat nilai menyerang dan bertahan sehingga diperlukan kesegaran jasmani yang baik".

Berdasarkan hal-hal yang telah diuraikan sebelumnya maka penelitian ini diharapkan dapat mengetahui peningkatan kesegaran jasmani melalui matakuliah pencak silat mahasiswa Ilmu Keolahragaan. Instrumen tes multy stage fitness test untuk mengukur kardiovaskular (VO2 Max) mahasiswa Ilmu Keolahragaan.

\section{METODE}

Jenis penelitian yang digunakan dalam penelitian ini adalah penelitian kuantitatif pendekatan pra eksperimen one group pretest-posstest design (sugiyono, 2016). Adapun desain dalam penelitian ini sebagai berikut: 


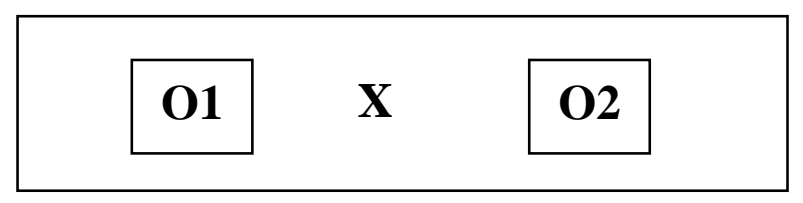

Gambar 1. Desain Penelitian

Keterangan:

O1 : pretest

$\mathrm{X} \quad$ : treatment

$\mathrm{O} 2$ : posttest

Objek yang akan diteliti dalam penelitian ini adalah peningkatan kesegaran jasmani melalui matakuliah pencak silat mahasiswa Ilmu Keolahragaan. Waktu penelitian dilaksanakan dari bulan Maret 2019 sampai dengan Agustus 2019. Lokasi penelitian dilaksanakan di Aula Olahraga, FKIP, Universitas Mercu Buana Yogyakarta. Populasi dalam penelitian ini adalah seluruh mahasiswa yang mengambil matakuliah Pencak Silat program studi Ilmu Keolahragaan di semester 2 berjumlah 38 mahasiswa. Sampel yang akan digunakan dalam penelitian ini adalah seluruh mahasiswa yang mengambil matakuliah Pencak Silat program studi Ilmu Keolahragaan. Sehingga teknik penarikan sampel dalam penelitian ini menggunakan total sampling (Sugiyono, 2012). Teknik pengumpulan data yang dilakukan dalam penelitian bersumber dari peserta didik. Data yang bersumber dari peserta didik dilakukan peneliti berupa: Tes Kesegaran Jasmani berupa Multy Stage Fitness Test. Instrumen dalam penelitian ini adalah menggunakan instrument Tes Kesegaran Jasmani, Multy Stage Fitness Test.

Adapun teknik analisis data dalam penelitian ini menggunakan uji prasyarat analisis yang meliputi uji normalitas dan uji homogenitas. Teknik analisis data yang digunakan menggunakan rumus uji t-test dan dilanjutkan pengujian hipotesis.

a. Untuk mencari pengaruh treatmen (uji $t$ test) (sugiyono, 2016):

$$
\mathrm{t}=\frac{\bar{X}-\mu_{o}}{s / \sqrt{n}}
$$

Keterangan:

$$
\begin{array}{ll}
\mathrm{t} & : \mathrm{t} \text { hitung } \\
\mathrm{x} & : \text { rata-rata hitung } \\
\mu_{\mathrm{o}} & : \text { rata-rata spesifik atau rata-rata tertentu (yang menjadi }
\end{array}
$$




$$
\begin{array}{ll} 
& \text { perbandingan) } \\
\mathrm{s} & \text { : standar deviasi sampel } \\
\mathrm{n} & \text { : jumlah sampel }
\end{array}
$$

b. Pengujian Hipotesis

Apabila $\mathrm{T}_{\text {hitung }} \geq \mathrm{T}_{\text {tabel( }(\alpha: 0,05)}$ maka hipotesis diterima, artinya signifikan.

Apabila $\mathrm{T}_{\text {hitung }} \leq \mathrm{T}_{\text {tabel }(\alpha: 0,05)}$ maka hipotesis ditolak, artinya tidak signifikan.

\begin{tabular}{|c|c|c|c|c|}
\hline & & PRETTEST & POSSTEST & $\begin{array}{c}\text { GAIN } \\
\text { SCORE }\end{array}$ \\
\hline \multirow[t]{2}{*}{$\mathrm{N}$} & Valid & 38 & 38 & 38 \\
\hline & Missing & 0 & 0 & 0 \\
\hline \multicolumn{2}{|c|}{ Mean } & 36,4605 & 40,4789 & 4,0184 \\
\hline \multicolumn{2}{|c|}{ Median } & 36,4000 & 40,5000 & 3,0500 \\
\hline \multicolumn{2}{|c|}{ Mode } & 40,50 & $37,40^{\mathrm{a}}$ & ,30 \\
\hline \multicolumn{2}{|c|}{ Std. Deviation } & 6,60076 & 6,46747 & 3,55162 \\
\hline \multicolumn{2}{|c|}{ Variance } & 43,570 & 41,828 & 12,614 \\
\hline \multicolumn{2}{|c|}{ Range } & 26,90 & 26,50 & 11,60 \\
\hline \multicolumn{2}{|c|}{ Minimum } & 23,90 & 28,90 & 00 \\
\hline \multicolumn{2}{|c|}{ Maximum } & 50,80 & 55,40 & 11,60 \\
\hline \multicolumn{2}{|c|}{ Sum } & 1385,50 & 1538,20 & 152,70 \\
\hline
\end{tabular}

\section{HASIL DAN PEMBAHASAN}

Tabel 1. Descriptive Statistics

a. Multiple modes exist. The smallest value is shown (IBM, 2014)

Berdasarkan tabel 1 dapat disimpulkan adanya peningkatan yang signifikan terhadap kesegaran jasmani mahasiswa program studi Ilmu Keolahragaan yang mengambil matakuliah pencaksilat di semester 2 tahun pelajaran 2018/2019. Berikut ini merupakan deskripsi data hasil penelitian prettest $(\mathrm{O} 1)$ dan posttest (O2) berdasarkan mean dan standar deviasi dalam tampilan histogram:

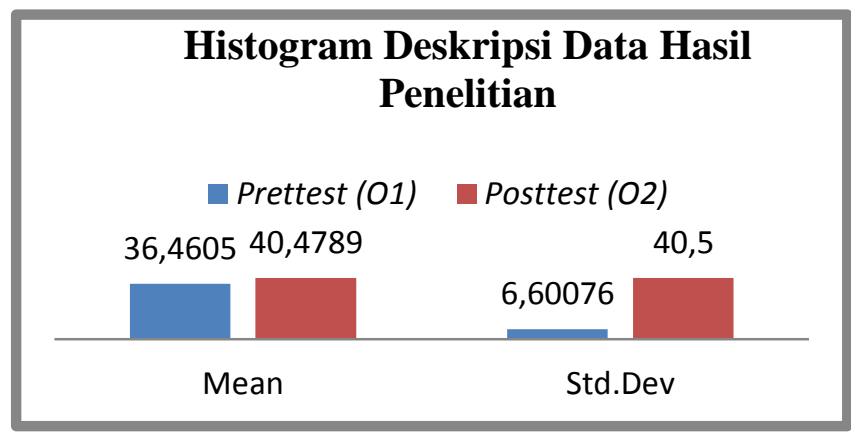

Gambar 2. Histogram Data Hasil Penelitian Prettest (O1) dan Posttest (O2)

Ginanjar Nugraheningsih. Peningkatan Kesegaran Jasmani Melalui Matakuliah Pencaksilat Mahasiswa Ilmu 
Berdasarkan gambar 2. dapat diamati bahwa $\mathrm{N}=38$, mean prettest $(\mathrm{O} 1)<$ posttest $(\mathrm{O} 2)=36,4605<40,4789$. Selain itu Std. Dev prettest $(\mathrm{O} 1)<$ posttest $(\mathrm{O} 2)=6,60076<40,5$. Dengan demikian dapat disimpulkan bahwa hasil posttest (O2) lebih baik daripada prettest $(\mathrm{O} 1)$ setelah diberikan treatment.

1. Uji Prasyarat Analisis

a. Uji Normalitas

Tabel 2. One-Sample Kolmogorov-Smirnov Test

\begin{tabular}{|c|c|c|}
\hline & & $\begin{array}{c}\text { Unstandardized } \\
\text { Residual }\end{array}$ \\
\hline $\bar{N}$ & & 38 \\
\hline Normal Parameters ${ }^{\mathrm{a}, \mathrm{b}}$ & Mean & ,0000000 \\
\hline & Std. & 3,38104410 \\
\hline Most Extreme Differences & Absolute &, 121 \\
\hline & Positive &, 121 \\
\hline & Negative &,- 090 \\
\hline Test Statistic & &, 121 \\
\hline Asymp. Sig. (2-tailed) & & $178^{\mathrm{c}}$ \\
\hline
\end{tabular}

a. Test distribution is Normal.

b. Calculated from data.

c. Lilliefors Significance Correction.

Berdasarkan table 2. diketahui bahwa nilai signifikansi Asiymp. Sig (2tailed) sebesar 0,178 > 0,05. Maka sesuai dengan dasar pengambilan keputusan dalam uji normalitas Kolmogorov-smirnov dapat disimpulkan bahwa data tersebut berdistribusi normal.

b. Uji Homogenitas

Uji homogenitas dalam penelitian ini menggunakan levene statistic aplikasi SPSS, sebagai berikut:

Tabel 3. Test of Homogeneity of Variance

\begin{tabular}{|ll|r|r|r|r|}
\hline & & $\begin{array}{r}\text { Levene } \\
\text { Statisti } \\
\mathrm{c}\end{array}$ & $\mathrm{df1}$ & $\mathrm{df2}$ & \multicolumn{1}{c|}{ Sig. } \\
\hline Hasil & Based on Mean &, 072 & 1 & 74 &, 789 \\
Kesegaran & Based on Median &, 073 & 1 & 74 &, 788 \\
Jasmani & Based on Median and &, 073 & 1 & 73,94 &, 788 \\
& with adjusted df & & & 6 & \\
& Based on trimmed & & \\
& mean &, 066 & 1 & 74 &, 798 \\
\hline
\end{tabular}


Berdasarkan table 3 diketahui sig. based on mean untuk variable hasil kesegaran jasmani adalah sebesar 0,789. Karena 0,789>0,05 maka dapat disimpulkan bahwa varians data hasil kesegaran jasmani pada data kelompok prettest $(\mathrm{O} 1)$ dan posttest $(\mathrm{O} 2)$ adalah homogen.

2. Uji Analisis Data Penelitian

a. Kondisi Kesegaran Jasmani Mahasiswa Putra dan Putri Program Studi Ilmu Keolahragaan Melalui Matakuliah Pencak Silat Sebelum Mengikuti Matakuliah Pencak Silat.

Tabel 4. Distribusi Frekuensi Kelompok Prettest (O1) Putra dan Putri sebelum Mengikuti MK Pencak Silat

\begin{tabular}{|c|c|c|c|c|c|c|}
\hline \multirow{2}{*}{$\begin{array}{c}\text { Jenis } \\
\text { Kelamin }\end{array}$} & \multicolumn{5}{|c|}{ Kategori } & \multirow[t]{2}{*}{ Total } \\
\hline & $\begin{array}{l}\text { Sangat } \\
\text { Kurang }\end{array}$ & Kurang & Sedang & Baik & $\begin{array}{c}\text { Sangat } \\
\text { Baik }\end{array}$ & \\
\hline \multirow{2}{*}{ Putra } & 2 & 8 & 18 & 7 & 0 & 35 \\
\hline & $0,05 \%$ & $0,21 \%$ & $0,47 \%$ & $0,18 \%$ & $0,00 \%$ & $0,92 \%$ \\
\hline \multirow[t]{2}{*}{ Putri } & 2 & 1 & 0 & 0 & 0 & 3 \\
\hline & $0,05 \%$ & $0,02 \%$ & $0,00 \%$ & $0,00 \%$ & $0,00 \%$ & $0,07 \%$ \\
\hline \multirow[t]{2}{*}{ Total } & 4 & 9 & 18 & 7 & 0 & 38 \\
\hline & $0,10 \%$ & $0,23 \%$ & $0,47 \%$ & $0,18 \%$ & $0,00 \%$ & $100 \%$ \\
\hline
\end{tabular}

Dari tabel 4 dapat dijelaskan bahwa kondisi kesegaran jasmani mahasiswa putra dan putri program studi Ilmu Keolahragaan melalui matakuliah pencak silat sebelum mengikuti matakuliah pencak silat yaitu untuk mahasiswa putra rata-rata pada kategori sedang yaitu 18 mahasiswa $(0,47 \%)$ dan untuk mahasiswa putri rata-rata pada kategori sangat kurang yaitu 2 mahasiswa $(0,05 \%)$. Sedangkan ratarata kondisi keseluruhan kesegaran jasmani mahasiswa program studi Ilmu Keolahragaan melalui matakuliah pencak silat sebelum mengikuti matakuliah pencak silat termasuk kategori sedang yaitu 18 mahasiswa $(0,47 \%)$.

Dari keterangan tersebut untuk lebih memperjelas disajikan dalam bentuk diagram histogram sebagai berikut: 


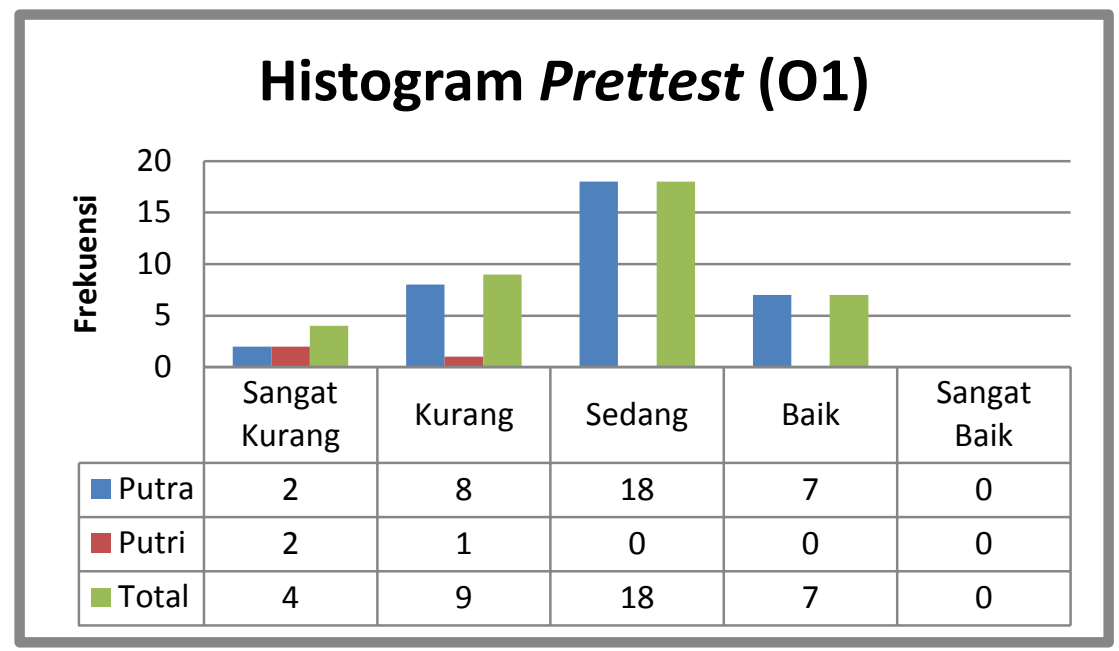

Gambar 3. Histogram Prettest (O1) Kesegaran Jasmani

Berdasarkan dari gambar 3. kondisi keseluruhan kesegaran jasmani mahasiswa program studi Ilmu Keolahragaan melalui matakuliah pencak silat sebelum mengikuti matakuliah pencak silat termasuk kategori sedang yaitu 18 mahasiswa $(0,47 \%)$.

b. Kondisi Kesegaran Jasmani Mahasiswa Putra Dan Putri Program Studi Ilmu Keolahragaan Melalui Matakuliah Pencak Silat Sesudah Mengikuti Matakuliah Pencak Silat.

Tabel 5. Distribusi Frekuensi Kelompok Posttest (O2) Putra dan Putri sesudah Mengikuti MK Pencak Silat

\begin{tabular}{|c|c|c|c|c|c|c|}
\hline \multirow{2}{*}{$\begin{array}{c}\text { Jenis } \\
\text { Kelamin }\end{array}$} & \multicolumn{5}{|c|}{ Kategori } & \multirow[t]{2}{*}{ Total } \\
\hline & $\begin{array}{l}\text { Sangat } \\
\text { Kurang }\end{array}$ & Kurang & Sedang & Baik & $\begin{array}{l}\text { Sangat } \\
\text { Baik }\end{array}$ & \\
\hline \multirow[t]{2}{*}{ Putra } & 0 & 5 & 17 & 12 & 1 & 35 \\
\hline & 0 & $0,13 \%$ & $0,44 \%$ & $0,31 \%$ & $0,02 \%$ & $0,92 \%$ \\
\hline \multirow[t]{2}{*}{ Putri } & 0 & 1 & 2 & 0 & 0 & 3 \\
\hline & 0 & $0,02 \%$ & $0,05 \%$ & 0 & 0 & $0,07 \%$ \\
\hline \multirow[t]{2}{*}{ Total } & 0 & 6 & 19 & 12 & 1 & 38 \\
\hline & 0 & $0,15 \%$ & $0,5 \%$ & $0,31 \%$ & $0,02 \%$ & $100 \%$ \\
\hline
\end{tabular}

Dari tabel 5. dapat dijelaskan bahwa kondisi kesegaran jasmani mahasiswa putra dan putri program studi Ilmu Keolahragaan melalui matakuliah pencak silat sesudah mengikuti matakuliah pencak silat yaitu untuk mahasiswa putra rata-rata pada kategori sedang yaitu 17 mahasiswa $(0,44 \%)$ dan untuk mahasiswa putri rata-rata pada kategori sedang yaitu 2 mahasiswa (0,05\%). Sedangkan rata-rata kondisi keseluruhan kesegaran jasmani mahasiswa program studi Ilmu 
Keolahragaan melalui matakuliah pencak silat sesudah mengikuti matakuliah pencak silat termasuk kategori sedang yaitu 19 mahasiswa $(0,5 \%)$.

Dari keterangan tersebut untuk lebih memperjelas disajikan dalam bentuk diagram histogram sebagai berikut:

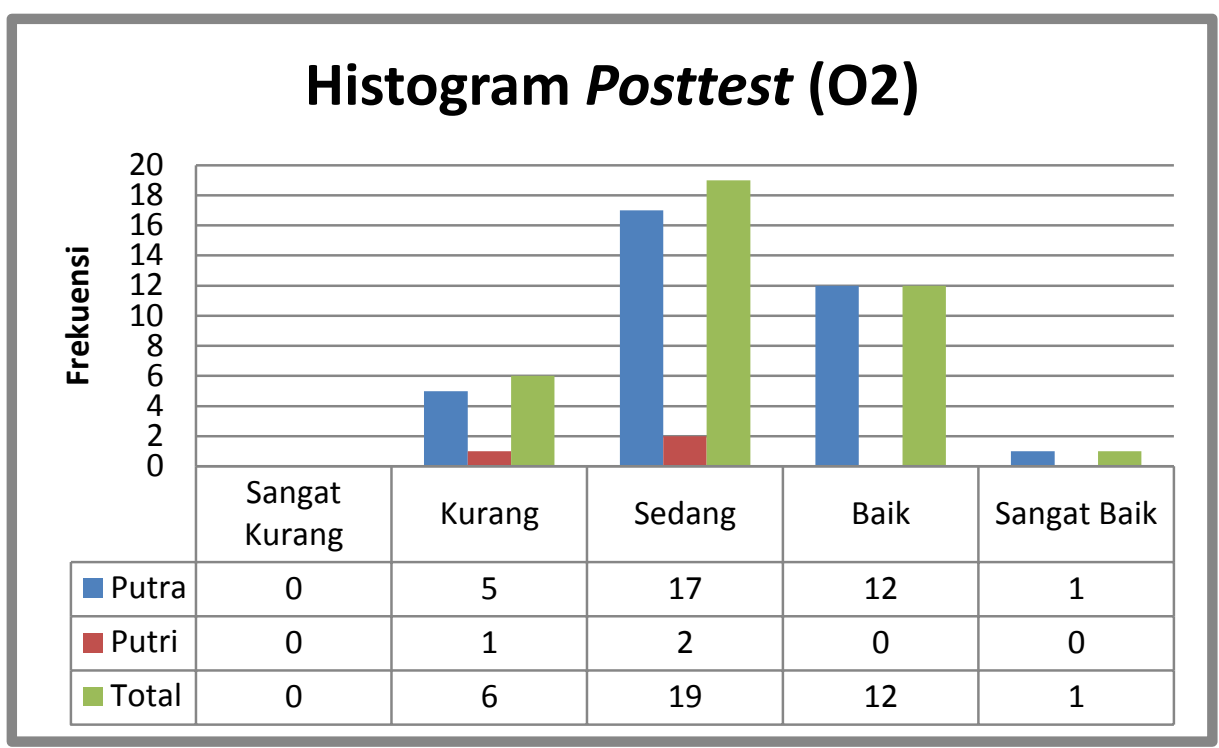

Gambar 4. Histogram Posttest (O2) Kesegaran Jasmani

Berdasarkan dari gambar 4. kondisi keseluruhan kesegaran jasmani mahasiswa program studi Ilmu Keolahragaan melalui matakuliah pencak silat sesudah mengikuti matakuliah pencak silat termasuk kategori sedang yaitu 19 mahasiswa $(0,5 \%)$.

c. Pengaruh Peningkatan Kesegaran Jasmani Melalui Matakuliah Pencaksilat Mahasiswa Ilmu Keolahragaan.

Uji analisis data pada penelitian ini menggunakan uji t-test untuk mencari pengaruh treatment. Adapun hasilnya sebagai berikut:

Tabel 6. Group Statistics T-Test

\begin{tabular}{|l|l|r|r|r|c|}
\hline & Kelompok & $\mathrm{N}$ & \multicolumn{1}{c|}{ Mean } & \multicolumn{1}{c|}{$\begin{array}{c}\text { Std. } \\
\text { Deviation }\end{array}$} & $\begin{array}{c}\text { Std. Error } \\
\text { Mean }\end{array}$ \\
\hline $\begin{array}{l}\text { Hasil Kesegaran } \\
\text { Jasmani }\end{array}$ & $\begin{array}{l}\text { Kelompok } \\
\text { Kelompok }\end{array}$ & 38 & 36,4605 & 6,60076 & 1,07078 \\
& O2 & 38 & 40,4789 & 6,46747 & 1,04916 \\
\hline
\end{tabular}


Berdasarkan tabel 6. diketahui jumlah data hasil kesegaran jasmani untuk kelompok O1 adalah 38 mahasiswa dan kelompok O2 adalah 38 mahasiswa. Nilai rata-rata untuk kelompok O1 sebesar 36,4605 dan untuk kelompok O2 sebesar 40, 4789. Dengan demikian secara deskriptif statistic dapat disimpulkan ada perbedaan rata-rata hasil kesegaran jasmani antara kelompok O1 (prettest) dengan kelompok O2 (posttest). Selanjutnya untuk membuktikan apakah perbedaan tersebut signifikan atau tidak maka dilanjutkan uji t-tes berikut ini.

Tabel 7. Independent Samples Test

\begin{tabular}{|c|c|c|c|c|c|c|c|c|c|c|}
\hline & \multicolumn{2}{|c|}{$\begin{array}{l}\text { Levene's Test } \\
\text { for Equality } \\
\text { of Variances }\end{array}$} & \multicolumn{7}{|c|}{ t-test for Equality of Means } \\
\hline & & \multirow[b]{2}{*}{$\mathrm{F}$} & \multirow[b]{2}{*}{ Sig. } & \multirow[b]{2}{*}{$\mathrm{t}$} & \multirow[b]{2}{*}{ df } & \multirow{2}{*}{$\begin{array}{l}\text { Sig. (2- } \\
\text { tailed) }\end{array}$} & \multirow{2}{*}{$\begin{array}{l}\text { Mean } \\
\text { Differen } \\
\text { ce }\end{array}$} & \multirow{2}{*}{$\begin{array}{l}\text { Std. } \\
\text { Error } \\
\text { Differen } \\
\text { ce }\end{array}$} & \multicolumn{2}{|c|}{$\begin{array}{l}95 \% \text { Confidence } \\
\text { Interval of the } \\
\text { Difference }\end{array}$} \\
\hline & & & & & & & & & Lower & Upper \\
\hline $\begin{array}{l}\text { Hasil } \\
\text { Kesegaran } \\
\text { Jasmani }\end{array}$ & $\begin{array}{l}\text { Equal } \\
\text { variances } \\
\text { assumed } \\
\text { Equal } \\
\text { variances } \\
\text { not } \\
\text { assumed }\end{array}$ &, 072 &, 789 & $-2,681$ & $\begin{array}{l}73,9 \\
69\end{array}$ &, 009 & $\begin{array}{l}4,01842 \\
- \\
4,01842\end{array}$ & 1,49911 & $\begin{array}{l}- \\
7,00546 \\
- \\
7,00548\end{array}$ & $\begin{array}{l}- \\
1,03139 \\
- \\
1,03136\end{array}$ \\
\hline
\end{tabular}

Berdasarkan tabel 7. nilai sig. (2-tailed) sebesar 0,009 $<0,05$ maka disimpulkan bahwa H0 ditolak dan Ha diterima. Dengan demikian dapat disimpulkan bahwa ada perbedaan yang signifikan antara rata-rata kelompok O1 (prettest) dan kelompok $\mathrm{O} 2$ (posttest).

\section{d. Pengujian Hipotesis dan Pembahasan}

Apabila $\mathrm{T}_{\text {hitung }} \geq \mathrm{T}_{\text {tabel( } \alpha: 0,05)}$ maka hipotesis diterima, artinya signifikan. Apabila $\mathrm{T}_{\text {hitung }} \leq \mathrm{T}_{\text {tabel( }(\mathrm{a}: 0,05)}$ maka hipotesis ditolak, artinya tidak signifikan. Diketahui nilai t hitung adalah sebesar 2, 681 sedangkan nilai t tabel dengan mengacu pada rumus $(\alpha / 2)$; (df) sama dengan $(0,05 / 2) ; 36=0,025 ; 36$. Maka ditemukan nilai $\mathrm{t}$ tabel sebesar 2.434 .

Dengan demikian diperoleh nilai $t_{\text {hitung }}>t_{\text {tabel }}=2,681>2,434$ (p value $=0,009<$ 0,05). Maka Ho ditolak dan Ha diterima, artinya ada perbedaan rata-rata kesegaran jasmani pretest dengan posstest. Perbedaan rata-rata (mean difference) sebesar $4,01842(40,4789-36,4605)$ posttest lebih tinggi daripada pretest. Melalui 
matakuliah pencak silat akan memberikan pengaruh peningkatan kesegaran jasmani.

Berdasarkan hasil dari penelitian ini ditemukan bahwa matakuliah pencak silat dapat memberikan pengaruh positif terhadap kesegaran jasmani seseorang. Hal ini sejalan dengan (Kuswanto, 2016), "Prinsip dasar olahraga pencak silat adalah membela diri yang di dalamnya terdapat nilai menyerang dan bertahan sehingga diperlukan kesegaran jasmani yang baik". Selain itu menurut (Resmana et al., 2014) yang dikutip (Biliandri et al., 2018), "Komponen dari kesegaran jasmani terdiri dari 10 komponen, yaitu: 1) kekuatan (strength), 2) daya tahan (endurance), 3) daya otot (muscular power), 4) kecepatan (speed), 5) daya lentur (flexibility), 6) kelincahan (agility), 7) koordinasi (coordination), 8) keseimbangan (balance), 9) ketepatan (accuracy), 10) reaksi (reaction). Apabila kesegaran jasmani yang dimiliki seseorang tersebut baik maka olahraga beladiri pencak silat itu juga akan baik. Kesegaran jasmani yang baik diperlukan dalam pencak silat.

\section{SIMPULAN}

Berdasarkan dari hasil penelitian yang telah dilakukan maka dapat disimpulkan bahwa nilai $\mathrm{t}_{\text {hitung }}>\mathrm{t}_{\text {tabel }}=2,681>2,434$ (p value $\left.=0,009<0,05\right)$. Maka Ho ditolak, artinya ada perbedaan rata-rata kesegaran jasmani pretest dengan posstest. Perbedaan rata-rata (mean difference) sebesar 4,01842 (40,4789$36,4605)$ posttest lebih tinggi daripada pretest. Melalui matakuliah pencak silat akan memberikan pengaruh peningkatan kesegaran jasmani.

Dari hasil penelitian mengenai peningkatan kesegaran jasmani melalui matakuliah pencaksilat mahasiswa Ilmu Keolahragaan ini, maka penulis mengajukan saran-saran sebagai berikut:

1. Bagi mahasiswa Ilmu Keolahragaan agar meningkatkan kesegaran jasmaninya guna menunjang prestasi akademik keilmuan olahraga.

2. Bagi masyarakat umum agar menjaga kesegaran jasmaninya karena penting bagi kesehatan tubuh.

3. Bagi peneliti yang akan datang hendaknya mengadakan penelitian lanjut tentang kesegaran jasmani. 


\section{DAFTAR RUJUKAN}

Biliandri, B., Supriyono, S., Pujianto, A., \& Priyono, B. (2018). Pengembangan Konservatif Games In Aquatic Untuk Meningkatkan Kebugaran Jasmani Dan Sportivitas Siswa Sekolah Dasar. Jp.jok (Jurnal Pendidikan Jasmani, Olahraga Dan Kesehatan). https://doi.org/10.33503/jpjok.v2i1.232

Hasan, S. (2008). Kesegaran jasmani atlet sepakbola.

IBM. (2014). IBM SPSS Statistics 22 Algorithms. Ibm.

Iswana, B., \& Siswantoyo, S. (2013). Model Latihan Keterampilan Gerak Pencak Silat Anak Usia 9-12 Tahun. Jurnal Keolahragaan. https://doi.org/http://dx.doi.org/10.21831/jk.v1i1.2343

Kuswanto, C. W. (2016). Penyusunan tes fisik atlet pencak silat dewasa kategori tanding. Jurnal Keolahragaan. https://doi.org/10.21831/jk.v4i2.6423

Mayanto, A. (2019). Model Pembelajaran Keterampilan Tendanga Pencak Silat (Akis) Untuk Anak SMA. Jp.jok (Jurnal Pendidikan Jasmani, Olahraga Dan Kesehatan). https://doi.org/10.33503/jpjok.v2i2.442

Permendikbud RI No. 20. (2016). Standar Kompetensi Lulusan Pendidikan Dasar dan Menengah. In Lampiran Peraturan Menteri Pendidikan dan Kebudayaan Republik Indonesia Nomor 20 Tahun 2016.

Prayuda, A. Y., \& Firmansyah, G. (2017). Pengaruh Latihan Lari 12 Menit Dan Lari Bolak Balik Terhadap Peningkatan Daya Tahan VO2 max. Jp.jok (Jurnal Pendidikan Jasmani, Olahraga Dan Kesehatan). https://doi.org/10.33503/jpjok.v1i1.247

Republik Indonesia. (2005). Peraturan Pemerintah Republik Indonesia Nomor 19 tahun 2005 tentang standar nasional pendidikan. Peraturan Pemerintah Republik Indonesia. https://doi.org/10.1017/CBO9781107415324.004

Resmana, B., Saichudin, -, \& Januarto, O. B. (2014). Survei Tingkat Kesegaran Jasmani Peserta Ekstrakurikuler Bola Basket SMA Negeri 2 Lumajang. Jurnal Pendidikan Jasmani. https://doi.org/10.17977/PJ.V24I1.4196

Saputro, Y. D. (2018). Survei Tingkat Kebugaran Jasmani Pada Siswa Putri Kelas VIII MTS Surya Buana Malang Tahun Pelajaran 2017/2018. Jp.Jok (Jurnal Pendidikan Jasmani, Olahraga Dan Kesehatan). https://doi.org/10.33503/jpjok.v1i2.170 
Setiawan, A. (2012). Pencapaian prestasi olahraga melalui kegiatan ekstrakurikuler pencak silat. Jurnal Pelopor Pendidikan.

Sugiyono. (2016). Metode Penelitian Pendidikan (Kuantitatif Kualitatif dan $R \&$ D). Bandung: Alfabeta. https://doi.org/10.1164/rccm.200409-1267OC

Sugiyono. (2012). Statistik Untuk Pendidikan. Bandung: Alfabeta

UUD 45. (1945). Undang-undang Dasar RI Tahun 1945. Departemen Kesehatan $R I$.

Widodo, B. S., \& Kusnanik, N. W. (2013). Tingkat Kesegaran Jasmani pada Siswa SMP Negeri 2 Krembung dan SMP Negeri 2 Sidoarjo. In Jurnal Prestasi Olahraga.

Yusuf, H. (2018). Evaluasi Kebugaran Jasmani Melalui Harvard Step Test pada Mahasiswa PJKR Tahun2016/2017 IKIP Budi Utomo. Jp.Jok (Jurnal Pendidikan. Jasmani, Olahraga Dan Kesehatan), 1(2), 1-13. 